\title{
"WHATSAPP": DE MENSAGEIRO INSTANTÂNEO E CHAMADA DE VOZ EM SMARTPHONES, PARA DISPOSITIVO DE COMUNICAÇÃO UBÍQUA DOS GESTORES EAD DA UFT/UAB NO CERRADO TOCANTINENSE
}

"Whatsapp": instant messenger and call voice in smartphones to device ubiquitous communication of managers of EAD UFT/UAB in vegetation tocantinense.

"WhatsApp": mensajería instantánea y llamada de voz en teléfonos inteligentes a dispositivo de comunicación ubicua de los administradores de EAD UFT / UAB en vegetación tocantinense.

\section{Damião Rocha* $^{1}$, Isabel Auler Pereira ${ }^{2}$, Valtuir Soares ${ }^{3}$}

${ }^{1}$ Universidade Federal do Tocantins (UFT). Docente do Programa de Pós-Graduação Stricto Sensu em Educação (PPGE). Diretor da Diretoria de Tecnologias Educacionais (DTE). Coordenador da Universidade Aberta do Brasil (UAB), Tocantins, Brasil.

${ }^{2}$ Universidade Federal do Tocantins (UFT). Docente Programa de Pós-Graduação Stricto Sensu em Educação (PPGE). Reitora da Universidade Federal do Tocantins (UFT), Tocantins, Brasil (in memoriam)

${ }^{3}$ Universidade Federal do Tocantins (UFT). Diretor Financeiro da Diretoria de Tecnologias Educacionais (DTE) e da Universidade Aberta do Brasil (UAB), Tocantins, Brasil.

*Correspondência: Diretoria de Tecnologias Educacionais /DTE, Av. NS 15, 109 Norte, Palmas, Tocantins, Brasil. CEP:77.010-090.e-mail: damiao@uft.edu.br

Artigo recebido em 27/03/2017 aprovado em 29/05/2017 publicado em 31/05/2017

\section{RESUMO}

O trabalho aborda o aplicativo multiplataforma "WhatsApp Messenger" e seu uso de mensageiro instantâneo online e de chamadas de voz para smartphones. Na EaD da Universidade Federal do Tocantins (UFT), esse aplicativo tem sido utilizado como dispositivo móvel estratégico de mobilidade de comunicação, uma vez que a gestão dos cursos e programas ofertados em 16 polos de apoio presencial ficam localizados à grandes distâncias da sede da Diretoria de Tecnologias Educacionais (DTE) que faz a gestão dos cursos de graduação em EaD, por meio do Sistema Universidade Aberta do Brasil (UAB). A UFT através de sua diretoria de EaD, possui 5 cursos de graduação com matrícula de 1.273 alunos, distribuídos em 52 turmas. A implantação do grupo de comunicação online de gestores EaD no App WhatsApp e sua interface com professores, coordenadores de polos, diretores dos campi tornou a comunicação e os gestores EaD ubíquos. Uma ressignificação do comunicar-se caracterizando-se pela multidimensionalidade do espaço indissociável da sua hipermobilidade, ou seja, sua mobilidade física expandida pelos aparatos móveis, como no caso do WhatsApp. Sua abordagem teórica resulta dos estudos e pesquisas no Programa de Pós-Graduação Stricto Sensu em Educação PPGE/UFT.

Palavras-chave: Aplicativo messenger; Comunicação ubíqua; Gestão EaD e cultura digital; Mobilidade

\section{ABSTRACT}

The paper addresses the multiplatform app "WhatsApp Messenger" and their use of online instant messaging and voice calls to smartphones. In Distance Education, Federal University of Federal University of Tocantins (UFT), this application has been used as a communication mobility strategic mobile since the management of courses and programs offered in 16 classroom support poles are located Board headquarters of large distances 
Educational Technology (DTE) that manages the undergraduate courses in distance education through the System Open University of Brazil (UAB). The UFT through its Board of distance education has 5 undergraduate courses with an enrollment of 1,273 students divided into 52 classes. The implementation of online communication group of distance education managers in the App WhatsApp and its interface with teachers, poles coordinators, directors of the campuses has made communication and managers DL ubiquitous. A redefinition of communicating characterized by the multidimensionality of the indivisible space of your hypermobility, that is, their physical mobility expanded by mobile devices, as in the case of WhatsApp. Its theoretical approach results from studies and research in the Stricto Sensu Postgraduate Program in Education PPGE/UFT.

Keywords: IM Application; Ubiquitous communication; Distance education and digital culture; Mobility.

\section{RESUMEN}

El trabajo en la aplicación multiplataforma "WhatsApp Messenger" y su uso de mensajería instantánea en línea y de llamadas de voz para smartphones. Na EaD de la Universidad Federal do Tocantins (UFT), este sistema ha sido utilizado como mecanismo estratégico de movilidad de la comunicación, una vez que una gestión de los cursos y programas de los programas de 16 polos de apoyo presencial ficam localizados en grandes distancias de la sede de la Diretoria De Tecnologías Educativas (DTE) que forman una gestión de los cursos de graduación en EaD, por medio del Sistema de la Universidad Aberta del Brasil (UAB). A través de su Directorio de EaD, ha 5 cursos de graduación con matrícula de 1.273 alumnos, distribuidos en 52 turmas. Una implantación del grupo de comunicación online de gestores EaD no App WhatsApp y su interfaz con los profesores, coordinadores de polos, los directores de los medios de comunicación y los gestores EaD ubíquos. Uma ressignificación do comunicar-se caracterizar-se en la multidimensionalidad del espacio indissociable de su hipermobilidad, o su movilidad física expandida por los aparatos móviles, como no caso de WhatsApp. Su enfoque teórico resultados de los estudios y las investigaciones no Programa de Pós-Graduación Stricto Sensu en Educación PPGE / UFT.

Palavras-chave: Aplicativo messenger; Comunicação ubíqua; Gestión EaD e cultura digital; Mobilidade

\section{INTRODUÇÃO}

Quando pesquisamos sobre o dispositivo WhatsApp Messenger, comumente este está descrito como um aplicativo multiplataforma de mensagens instantâneas e chamadas de voz para smartphones. E ainda, que além de mensagens de texto, os usuários podem enviar imagens, vídeos, mensagens de áudio de mídia e, na nova atualização, podem ligar para qualquer contato de sua agenda que possua WhatsApp.

\section{WhatsApp: atualizando ...}

As pesquisas de uso e acesso de aplicativos disponíveis, apresentam dados que contabilizados somam mais de 30 bilhões de mensagens enviadas diariamente pelo WhatsApp. Nessa vibe um usuário médio passa mais de três horas por semana conectado somente neste aplicativo. O WhatsApp é o aplicativo mais usado pelos brasileiros revelam diversas pesquisas na rede. Ele é utilizado por $95 \%$ dos usuários brasileiros, seguido pelo Skype, com $81 \%$ e $68 \%$ do Facebook Messenger.

$\mathrm{Na}$ lista de hábitos dos brasileiros aparecem aqueles que já acordam com o celular na mão (24\%) e os que usam enquanto assistem TV, que perfazem $34 \%$. Os usuários fazem muitos downloads de aplicativos no celular, mas a preferência são aqueles de redes sociais.

Tratando-se de aplicativo não se pode deixar de abordar sobre o celular. Em uma das pesquisas divulgada na internet, diz-se que a "Unesco mostrou que $67 \%$ dos estudantes de países em desenvolvimento e emergentes, que leem pelo celular consideram o aparelho conveniente para a leitura, porque o dispositivo está o tempo todo com o usuário. Afinal, a mobilidade, disponibilidade de WiFi e redes móveis também nas instituições de ensino permitem o acesso a conteúdo com qualidade". 
O celular praticamente tornou-se controle remoto de acesso ao mundo. $\mathrm{O}$ que significava antes estar em frente a uma tela de computador, com teclado e mouse na mão e conectar-se ou desconectar-se desse ambiente, muda de significado. Os aplicativos de comunicação se constituem então na nova interface entre real e virtual. A telefonia móvel, o celular, por exemplo, é um representante desse interfaceamento, já diziam as pesquisas nos primeiros anos dos anos 2.000.

Para Lemos (2007), já no início dos anos 2.000 , os celulares eram "teletudo" e "controle remoto do cotidiano", os podcasts, o uso de SMS conhecido como smart mobs, dentre outras tecnologias móveis, apresentavam-se como uma categoria nova de conexão que possibilitava a mobilidade. As tecnologias móveis inauguraram a "era da conexão" (Lemos, 2007). Através dos serviços de celulares GSM e G3, redes sem fio, conhecida como "Wi-Fi" ou "internet wireless", redes Bluetooth, disponibilizaram-se novos formatos de acesso em substituição aos cabos seriais e USB da banda-larga UWB.

O celular é um dispositivo característico da cultura do computador. Cibercultura e ciberespaço são conceitos centrais na obra de Pierre Lévy desde o final dos anos 1990.

Conforme publicado na Wikipédia "competindo com uma série de serviços com base na Ásia, o WhatsApp cresceu de 2 bilhões de mensagens por dia em abril de 2012 para 10 bilhões em agosto do mesmo ano. De acordo com o Financial Times, o WhatsApp "tem feito para SMS em celulares o que o Skype fez para chamadas internacionais em telefones fixos". Em junho de 2013, o aplicativo alcançou a marca dos 250 milhões de usuários ativos e 25 bilhões de mensagens enviadas e recebidas diariamente".

\section{Interatividade nos Apps}

O WhatsApp é considerado uma nova forma de comunicação, de interatividade, uma vez que, por esse aplicativo, todos os usuários que fazem parte do seu contato de telefone podem se comunicarem gratuitamente, bastando apenas estar interligados ao aplicativo e adicionar contatos. Outro detalhe importante do WhatsApp é que não tira a privacidade e se pode optar por estar disponível ou não para determinadas pessoas. Há opção on ou off line, de interagir ou não, inclusive silenciando grupos.

Apesar de controverso, há interatividade quando o processo comunicativo está imbuído de uma concepção que contemple "[...] complexidade, multiplicidade, não linearidade, bi-direcionalidade, potencialidade, permutabilidade (combinatória), imprevisibilidade etc, permitindo ao usuáriointerlocutor-fruidor a liberdade de participação, de intervenção, de criação" (Silva, 2002: 100).

A interatividade como possibilidade de mutabilidade instantânea, como a concebemos atualmente, tem seu desenvolvimento a partir das pesquisas do Massachussets Institute of Technology MIT em 1970, a partir dos Interactive Computer Graphics, considerando que, até aquele momento, desenhos, figuras geométricas e outros formatos não podiam ser modificados em tempo real. Para (Bret, Couchot e Tramus, 2003):

A interatividade, entretanto, não se limita a permitir ao espectador conversas com a imagem; ela se estendeu, pouco a pouco, aos próprios objetos virtuais simulados pelo computador. À interatividade exógena que se estabelecia entre o espectador e a imagem, acrescenta-se a interatividade endógena que regula o diálogo dos objetos virtuais entre eles, quer sejam bi ou tridimensionais, abstratos ou de aparência realista. A interatividade endógena permite criar objetos capazes de perceber certas características (forma, cor, posição, velocidade de deslocamento etc.) próprias a outros 
objetos e ainda de manter relações mais ou menos complexas com estes (Bret, Couchot e Tramus, 2003: p.28-29).

O desenvolvimento da interatividade com a evolução da modelagem, utilizada para a realização de imagens numéricas, vai dos autômatos, passa pelas redes neurais, redes virtuais, inteligência virtual e chega aos objetos virtuais com todas as suas possibilidades de performance, assim como nos atuais Apps.

\section{WhatsApp: suas funcionalidades}

Com o WhatsApp por exemplo, é possível escolher entre comunicar pelo chat, envio de e-mail, enviar fotos da galeria, fazer upload de vídeos de sua galeria, gravar um áudio ou anexar da galeria de música e enviar para o interlocutor que a recebe imediatamente caso esteja com acesso à internet, ou seja várias possibilidades de interação.

Outra característica do WhatsApp é que o mesmo possui uma ferramenta de localização que identifica com exatidão onde se está, caso esteja perdido pode-se enviar sinal para um amigo que tem WhatsApp que ele pode chegar até você. A partir do momento que instala o aplicativo já pode-se comunicar, ele só não recebe ou envia mensagens se você não estiver online. De acordo com (Bauman, 2004):

Uma mensagem brilha na tela em busca de outra. Seus dedos estão sempre ocupados: você pressiona as teclas, digitando novos números para responder às chamadas ou compondo suas próprias mensagens. Você permanece conectado, mesmo estando em constante movimento, e ainda que os remetentes ou destinatários invisíveis das mensagens recebidas e enviadas também estejam em movimento, cada qual seguindo suas próprias trajetórias (Bauman, 2004, p.78).

Permanente conexão, o WhatsApp tornou-se um dos aplicativos mais populares ultimamente, chegando a marca de 700 a 900 milhões de usuários ativados mensalmente. Não se tem nas redes como verificar o grau de veracidade das pesquisas, amostras, enquetes que são divulgadas, no entanto com a margem de erro para mais ou para menos, o que nos importa aqui é abordar nesse trabalho a sua praticidade de comunicação como aplicativo de interação considerado de tecnologia amigável.

O App é totalmente gratuito e traz diversos emojis, com a opção de gravar áudios e de criar grupos de até 100 pessoas. Como referimos anteriormente, as estatísticas mostram que o WhatsApp já ultrapassou os 700 milhões e chegou a 900 milhões de usuários ativos mensalmente, que trocam mais de 600 milhões de fotos e 64 bilhões de mensagens por dia.

Os aplicativos de mensagens continuarão crescendo em ritmo acelerado é o que mostram as tendências de mercado e consumo. Os quatro principais Apps do gênero (WhatsApp, Snapchat, LINE e WeChat) cresceram a uma taxa $15 \%$ por trimestre em 2014.

Desde a aquisição pelo Facebook o WhatsApp acrescentou mais 200 milhões de usuários à sua base. Já o Facebook Messenger, App dedicado exclusivamente à troca de mensagens entre usuários do Facebook, já possui mais de 500 milhões de usuários ativos.

Isso significa que em pouco tempo, Apps de mensagens podem ser maiores que as redes sociais e talvez esse fato justifique a compra do WhatsApp por US\$ 22 bilhões e a tentativa de compra do Snapchat por US\$ 3 bilhões pelo Facebook.

Há muitas facilidades que tornam o WhatsApp um dos aplicativos mais utilizados. Quaisquer desenvolvedores de softwares repercutem suas 
características em relação a outros dispositivos de comunicação instantânea. Ele é mais rápido e prático para responder. A pessoa que recebe a mensagem no aplicativo, responde com maior rapidez em relação ao e-mail, por exemplo. Basta apenas ler e responder, ao contrário do e-mail que muitas vezes demora a receber, há a leitura, mas não há a resposta ou há demora de dias para o retorno da mensagem.

No WhatsApp se sabe quando a outra pessoa recebeu a mensagem. $O$ recurso de saber quando a pessoa recebe a mensagem e quando ela é lida, facilita muito a interface de comunicação, pois se sabe se a mensagem foi lida ou não. $\mathrm{O}$ envio de imagens, sons e vídeos de forma fácil e rápida é outra facilidade. Tirou foto, filmou algo ou quer enviar uma mensagem de voz, é possível de ser feito com apenas um clique. Não precisa anexar arquivo e não tem restrição de tamanho.

$\mathrm{O}$ envio de mensagem de voz sem complicações é outra funcionalidade do aplicativo. Apenas pressiona-se o desenho do microfone na tela e grava-se a mensagem. Isto é, sem dificuldade, e a mensagem de voz pode impactar ainda mais do que a mensagem de texto escrito.

O conteúdo distribuído pelo WhatsApp se torna mais viral por ser mais usual. Como já está na mão de seu contato, se pode enviar uma mensagem, vídeo, imagem ou voz com um conteúdo que pode ser compartilhado inúmeras vezes, consequentemente a "viralização".

Com o WhatsApp não se tem o risco de cair na caixa de spam. Não há caixa de spam no WhatsApp, logo, se pode enviar mensagens sem problemas. A pessoa é avisada sobre a mensagem logo que recebeu. Logo que se envia a mensagem, a pessoa é notificada e vê pelo menos 65 caracteres da mensagem enviada.

A cultura wireless ou da comunicação sem fio transformou a separação do físico com o digital em combinação entre eles. "[...] A emergência de tecnologias portáteis contribuiu para a possibilidade de se estar constantemente conectados a espaços digitais e de, literalmente, se "carregar" a Internet aonde quer que se vá" (Silva, 2006: 27).

Independentemente da forma de conexão ou interface, os usuários procuram por sociabilidade. "Encontrar outros usuários para socializar no ciberespaço sempre foi uma das importantes funções dos ambientes de multiusuários da Internet. A diferença, no entanto, é que as redes móveis ajudam a encontrar outros indivíduos em espaços públicos" (Silva, 2006: 40).

A cultura de acesso criou um novo espaço, um “espaço híbrido” (Silva, 2006), a partir dos conceitos de "realidade aumentada" e "realidade mista". Para Silva (2006), espaço híbrido “[...] ocorre quando não mais se precisa "sair" do espaço físico para entrar em contato com ambientes digitais" (Silva, 2006: 28).

A "realidade aumentada", nesse contexto, equivale a três formatos: a utilização dos capacetes de realidade virtual; a computação gráfica e sua possibilidade de aumentar qualquer objeto virtual e um mix de ambientes virtuais e reais que seria a "realidade mista”. A partir da discussão de realidade aumentada e mista, define-se o espaço híbrido como espaço conceitual. Segundo (Silva, 2006):

[...] um espaço conceitual criado pela fusão das bordas entre espaços físicos e digitais, devido ao uso de tecnologias móveis como interfaces sociais. Entretanto, um espaço híbrido NÃO é construído por tecnologia. É, sim, criado pela conexão de mobilidade e comunicação, e materializado por redes sociais desenvolvidas simultaneamente em espaços físicos e digitais. Espaços móveis são espaços sociais conectados definidos pelo uso de interfaces portáteis como os nós da rede (Silva, 2006, p.32).

À ideia de espaço agrega-se a de "presença" que está relacionada ao conceito de telepresença. Esse por sua vez, descrevia as primeiras experiências da sensação que alguém teria, operando remotamente uma 
máquina. Isto é, a sensação de estar em um lugar diferente, através de um sistema de teleoperação.

Atualmente a telepresença é um termo descritivo do contexto da realidade virtual, em que os mediadores dessa experiência pode ser uma mídia ou também um aplicativo, que dão a impressão do usuário estar fisicamente presente em um espaço ou tempo tanto real como diferentemente imaginado daquele que realmente está.

\section{O grupo de gestores EaD no WhatsApp}

No entremeio da presencialidade e mediação, na UFT a educação a distância iniciou como experiência piloto em 2006. De lá para cá com a expansão do Sistema Universidade Aberta do Brasil (UAB) ampliaram-se as vagas, cursos e polos e aumentaram o número de gestores, tutores, coordenadores de polos, alunos envolvidos nessa modalidade na Universidade, que dificultou se fazer presente, visitar in loco cada um de seus polos em um mesmo semestre letivo. Essa equipe está composta de 8 coordenadores de cursos, 8 coordenadores de tutoria, 16 coordenadores de polos, 79 professores, 202 tutores, perfazendo um total de 313 gestores EaD.

A UFT é uma instituição multicampi e além dessa dispersão geográfica, a EaD como política de acesso e expansão é ofertada nos polos de localidades e municípios onde não se tem campus universitário e nem curso superior presencial.

Como estratégia de comunicação, com base na "ecologia das mídias" de uma sociedade mediatizada e midiatizada, na gestão de 2012 a 2016 a Diretoria de Tecnologias Educacionais (DTE) criou um grupo no WhatsApp, com 30 membros, dentre estes, o diretor e coordenador $\mathrm{UAB}$, o coordenador adjunto $\mathrm{UAB}$, assessores, estagiários da diretoria, todos os coordenadores de cursos, coordenadores de tutoria, coordenadores de estágios e TCC, técnicosadministrativos da diretoria e passou a usar o App como dispositivo instantâneo de conversas, envio de vídeos, imagens de textos e áudio, tornando as decisões dos gestores EaD mais ágeis, coletivas e participativas, principalmente aos sábados e domingos, no momento das atividades docentes e acadêmicas nos polos de apoio presencial em que a Universidade fica sem o suporte de técnicos administrativos, por ser final de semana e de descanso, para mediar a comunicação e resolver pendências e problemas de plataformas e salas virtuais de aprendizagens.

Os documentos oficiais do Governo Federal, da Reitoria, da Diretoria são compartilhados em “computação em nuvem" (cloud computing), isto é, a utilização da memória e das capacidades de armazenamento e cálculo de computadores e servidores compartilhados e interligados por meio da internet, seguindo o princípio da computação em grade.

O serviço de armazenamento e acesso aos arquivos oficiais é feito pelo Dropbox, baseado no princípio do cloud computing. Experiência que suscitou a discussão da usabilidade e acessibilidade da educação mediada por tecnologias, a mudança de hábito da comunicação presencial, colocou em xeque os agendamentos com dia e hora marcada para despachar com o diretor, diminuindo as decisões com longas conversas por telefones fixos, propiciando a discussão da comunicação ubíqua, apesar dos problemas de conexão com a banda larga.

\section{Gestores EaD imersivos ubíquos}

A computação ubíqua (em inglês: Ubiquitous Computing ou ubicomp) ou computação pervasiva é um termo usado para descrever a onipresença da informática no cotidiano das pessoas. A computação ubíqua (Santaella, 2013), envolve a integração da mobilidade com os sistemas de presença distribuída. 
Quando consideramos que o WhatsApp propiciou o debate sobre o perfil de "gestores $\mathrm{EaD}$ imersivos ubíquos", estamos tratando da ideia de se estar sempre presente e acessível em qualquer tempo e lugar por meio do WhatsApp, inclusive nos 16 polos de apoio presencial ao mesmo tempo no horizonte da ubiquidade (Santaella, 2013):

Constatada a existência de dois espaços igualmente físicos, mas fisicamente diferenciados, o espaço ciber, ou seja, a nuvem informacional que nos envolve, e o espaço de circulação de nossos corpos, constatado também o fato de que, dotados de dispositivos móveis, podemos nos mover no mundo físico e, ao mesmo tempo, acessar o espaço da nuvem informacional que nos rodeia, pode-se afirmar que está aberto para nós o horizonte da ubiquidade. De fato, nessas condições estamos em dois espaços ao mesmo tempo. Independente dos ritmos estabelecidos de trabalho e descanso, de estudo e lazer, a vida escoa não mais na mera sequencialidade temporal em locais físicos determinados, mas a isso se sobrepõe o escoamento da vida na intermitência do tempo em espaços reticulares (Santaella, 2013, p.137)

Essa vida ubíqua das redes sociais, especialmente no Facebook, trouxemos para a gestão da $\mathrm{EaD}$. Um debate que perpassa pela questão da aprendizagem ubíqua, co-presença, presença ausência, em especial, quando concebemos a $\mathrm{EaD}$ como modalidade multimodal, educação mediada.

\section{RESULTADOS E DISCUSSÃO}

Nessa experiência quando nos referimos ao WhatsApp como interface estamos considerando a interatividade como característica fundante desse aplicativo. Uma interface pode ser definida como mediadora de relações comunicacionais. "O papel da interface é de traduzir informação digital do computador para o ser humano, de modo a torná-la compreensível para nós" (Silva, 2006, p.23).

Decorre dessa experiência a ideia de "interface social", que se define como "[...] um meio digital que intermedeia relações entre dois ou mais usuários. Assim, as interfaces sociais não apenas (re)definem relações comunicacionais, mas também (re)conceitualizam o espaço em que essas interações ocorrem" (Silva, 2006, p.23).

Interface" tornou-se uma palavra chave desde que o computador virou uma máquina dialogante. Sem interface não há interatividade, outra palavra chave. Em um sentido genérico e técnico, interface é definida como ambientes que permitem que dois ou mais sistemas mútuos se adaptem. Quando duas entidades tão distintas quanto a máquina e o humano pretendem entrar em conversação, é preciso haver recursos na superfície da primeira adaptáveis aos sentidos por meio dos quais o humano apreende e responde aos estímulos e apelos do mundo (Santaella, 2013, p.56).

A vida, na atualidade, passa a ser presidida por "mudanças instantâneas e erráticas". Os hábitos arraigados, as estruturas cognitivas sólidas, os valores estáveis, prevalecentes na modernidade sólida começam a se tornar desvantagens. A intensidade e a velocidade são dimensões marcantes dos tempos de agora.

[...] nossas instituições, valores de referência, estilos de vida, crenças e convicções mudam antes que haja tempo para sua solidificação em costumes, hábitos e verdades "auto-evidentes". Embora isso tudo já estivesse presente no passado relativamente recente da antiga ordem industrial, uma vez que ela se caracteriza pela mudança, está se fazia com breves paradas, fixando raízes; agora, tudo, empregos, relacionamentos, conhecimentos etc, tende a permanecer em rápido fluxo, volátil, flexível (Carmo, 2007, p.161). 
As influências da cultura pós-moderna sobre a vida são evidentes e possuem um componente estratégico desse desenvolvimento que são as tecnologias digitais e seus diversos aplicativos. Com a internet, ocorreu a descentralização da informação, o modelo hierarquizado de comunicação (um-todos) altera-se para tomada de decisão, com possibilidades de participação coletiva (todos-todos).

Muda-se de hábitos de uma técnica de controle para um modelo pulverizado em conexões, característico da chamada sociedade pós-moderna. Se a vida acontece em suas múltiplas linguagens líquidas, por que a educação mediada, que se quer hiper e transmídia não se utiliza dessas mesmas linguagens como a "gamificação"? As telas de computadores, de celulares são principalmente interfaces de interfaces

A tela do computador apresenta uma interface que intercepta o olhar do Outro. De não ver nada, de não ver o outro sujeito, passa-se a uma construção imaginária. O simbólico está ali e o imaginário está sempre estruturado pela ordem simbólica. O campo visual estrutura-se por leis simbólicas [...]. Discernir o que na tela se encontra encoberto, não-visível, envolve ainda um processo necessário de subjetivação na cultura digital (Gomez, 2004, p.82).

Discernir a tela, atividade cognoscente, base da educação e da formação em $\mathrm{EaD}$, que na vivência da estética da comunicação, é feita de "[...] hiatos, intervalos, desconexões, saturamento e dispersão" (Beiguelman, 2006, p.161), constituem traços importantes no contexto da mobilidade.

A contemporaneidade desafia a "[...] pensar o impacto epistemológico, semiótico e político da cultura da mobilidade, que se anuncia para além e por meio dos novos dispositivos de comunicação sem fio" e seus aplicativos e aplicabilidades diversos.

A multiconexão, a hipermobilidade não garantem por si mesmas a dialogicidade. A pessoa em interação mediada não suprime a necessidade de relacionamento físico e presencial interpessoal, até mesmo os usuários imersivos do ciberespaço que vivem com celular à mão. Todavia, um aplicativo de comunicação como o WhatsApp converge, transcodifica, sociabiliza, prolifera a interatividade das pessoas em tempo real.

A rede não tem um centro, mas diversos centros. "A rede que captura e que ampara, que distribui e abastece, canaliza e entrelaça, transmite e comunica, interliga e acolhe" (Ramal, 2002: 186).

As ambiguidades da presença ausente, a dupla mobilidade, as bordas entre os espaços de presença e ausência diluídos, chamam-nos a atenção para o intercambio, a sobreposição, em um mesmo espaço, por meio da vivência da ubiquidade que os aplicativos potencializam, e nesse caso, o WhatsApp poderá nos tornar cidadãos melhores conectados, interfaceados e enlaçados, depende dos nossos motivos, interesses e do nosso compromisso social e ético.

\section{AGRADECIMENTO}

Agradecemos ao "Projeto Rede de Educação Mediada por Tecnologias para Formação Continuada de Docentes, Profissionais e Trabalhadores da Educação do Tocantins" (UFT/DTE/FAPTO) pelo apoio à apresentação desse trabalho no XII Congresso Brasileiro de Ensino Superior a Distância e I Congresso Internacional de Ensino Superior a Distância, realizado na cidade de Salvador, entre os dias 30 de novembro a 03 de dezembro de 2015, que teve como Tema: "Cultura Digital e Inovação: tecnologia educacional e dispositivos móveis".

Todos os autores declararam não haver qualquer potencial conflito de interesses referente a este artigo.

\section{REFERÊNCIAS}

BAUMAN, Zygmunt. Dentro e fora da caixa de ferramentas da sociabilidade. In: Amor líquido: sobre 
a fragilidade dos laços humanos. Rio de Janeiro, RJ: Jorge Zahar, 2004

BEIGUELMAN, Giselle. Entre hiatos e intervalos (a estética da transmissão no âmbito da cultura da mobilidade). In: ARAUJO, Denize Correa. (Org.). Imagem (ir)realidade: comunicação e cibermídia. Porto Alegre: Sulina, 2006.

BRET, Michel. COUCHOT, Edmond e TRAMUS, Marie-Hélène. A segunda interatividade. Em direção a novas práticas artísticas. Tradução de Gilse Boscato Muratore e Diana Domingues. In: DOMINGUES, Diana. Arte e vida no século XXI: tecnologia, ciência e criatividade. São Paulo, SP: Editora UNESP, 2003.

CARMO, Paulo Sérgio do. Sociologia e sociedade pósindustrial. São Paulo, SP: Paulus, 2007. GOMEZ, Maragarita Victoria. Educação em rede: uma visão emancipadora. São Paulo, SP: Cortez e IPF, 2004.

LÉVY, Pierre. Cibercultura. São Paulo: Editora 34, 1999.

LEMOS, André. Cibercultura e mobilidade: a era da conexão. Texto digital. In: Razón y Palabra. Revista Eletrônica $\quad \mathrm{N}^{\mathrm{o}} \quad 41$, outubro-novembro, 2004, www.razonypalabra.org.mx. Consulta realizada em maio de 2007.

RAMAL, Andrea Cecilia. Educação na cibercultura: hipertextualidade, leitura, escrita e aprendizagem. Porto Alegre, RS: Artmed, 2002.

SANTAELLA, Lucia. Comunicação ubíqua: repercussões na cultura e na educação. São Paulo, SP: Paulus, 2013

SANTAELLA, Lucia. Linguagens líquidas na era da mobilidade. São Paulo, SP: Paulus, 2007.

SANTAELLA, Lucia. Navegar no ciberespaço: o perfil do leitor imersivo. São Paulo, SP: Paulus, 2004.
SILVA, Adriana de Souza e. Do ciber ao híbrido: tecnologias móveis como interfaces de espaços híbridos. In: ARAUJO, Denize Correa. (Org.). Imagem (ir)realidade: comunicação e cibermídia. Porto Alegre: Sulina, 2006. 